\title{
Inhibition of Expression of a Mouse $\alpha$-Globin Gene by Plasmids that Include Antisense Oligonucleotides
}

\author{
Kazushige Yokoyama ${ }^{1,2 *}$, De-Xing Hou ${ }^{1}$, Hui Gao ${ }^{1}$, Xiaoren Tang ${ }^{1}$, Issay Kitabayashi ${ }^{1}$, Kazuko \\ Nishikura $^{3}$ and Gabriel Gachelin ${ }^{2}$ \\ ${ }^{1}$ Gene Bank and ${ }^{2}$ Laboratory for Molecular Regulation of Aging, Tsukuba Life Science Center, RIKEN (The In- \\ stitute of Physical and Chemical Research), 3-1-1 Koyadai, Tsukuba, Ibaraki 305, Japan, and ${ }^{3}$ Department of \\ Anatomy, The Wistar Institute, 36th and Spruce Streets, Philadelphia, PA 19104, USA
}

Key words: $\alpha$-globin/antisense RNA/erythroleukemia MEL cells/c-myc expression

\begin{abstract}
Plasmid-borne DNAs, corresponding to 68-base oligodeoxynucleotides, synthesized in the antisense or sense configuration and based on the nucleotide sequences of various regions of the mouse $\alpha$-globin mRNA, were introduced with the gene for xanthine-guanine phosphoribosyl transferase from $E$. coli (Ecogpt) into mouse erythroleukemia (MEL) cells by protoplast fusion. Specific inhibition of the synthesis of $\alpha$-globin was observed only in the cells transformed with the plasmids with antisense 68-mers that corresponded to the cap site as well as the site of initiation of translation of $\alpha$-globin mRNA (Oligo-A); Other plasmids with antisense 68-mers that corresponded to the regions of the exon/intron junctions, the individual exons, or the $3^{\prime}$ untranslated region were ineffective. This antisense RNA efficiently reduced the production of $\alpha$-globin to 9-18\% of the endogenous level after induction with hexylmethylene-bis-acetoamide (HMBA). Moreover, most of the antisense transformants did not show any decrease in the expression of the $c$-myc gene at the early phases of differentiation of MEL cells. Thus, we propose a hypothesis that the early decline in levels of $c$-myc mRNA may be independent of and uncoupled from the program of globin synthesis during the differentiation of MEL cells.
\end{abstract}

Mouse erythroleukemia (MEL) cells have been characterized as virally transformed erythroid precursors that are arrested at or before the proerythroblast stage of maturation of adult red cell. These cells can be induced to differentiate by various agents (32). Treatment with hexylmethylene-bis-acetoamide (HMBA) or dimethylsulfoxide (DMSO) results in a series of coordinated morphological and biochemical changes that mimic the events during the normal differentiation of erythroid cells (21). The continuous presence of an inducer is not required for terminal differentiation of MEL cells. After a latent period of treatment with inducer, which lasts for $18 \mathrm{~h}$, increasing numbers of cells become irreversibly committed to differentiation $(9,12)$, with a resultant significant increase in the rate of synthesis of globin mRNA and hemoglobin (21). Accumulation of globin mRNA, which is due to increased transcription of the globin gene (11), proceeds in the absence of inducer once commitment has occurred. The molecular mechanisms that lead to this irreversible commitment are not well understood.

The changes that occur in the level of $c-m y c$ mRNA during the first $18 \mathrm{~h}$ of treatment with inducer are apparent before any cells can be detected in the culture that

\footnotetext{
* To whom correspondence and requests for reprints should be ad-
} dressed. have become irreversibly committed to a program of terminal erythroid differentiation. The timing of these changes suggests the possibility that the early decline in levels of $c-m y c$ mRNA and the subsequent reexpression of $c-m y c$ may be important events in the decision of individual MEL cells to enter the differentiation program $(2,15,16,27)$. Previous studies have shown that the constitutive expression of transfected $c$-myc sequences in MEL cells inhibits the chemically induced differentiation of such cells, whereas the expression of antisense transcripts of $c-m y c$ accelerates this process $(4,5,17$, 26). Using techniques involving antisense RNA $(3,13$, $33,34,35$ ), we have investigated the relationship between the inducible expression of the mouse $\alpha$-globin gene and the molecular changes that occur when an erythroid cell becomes committed to cell growth and/or differentiation.

To study the specificity of the inhibition of the induced synthesis of globin in the antisense transformants, we used antisense oligomers that corresponded to various regions of the mouse $\alpha$-globin gene (25). A high degree of inhibition of the synthesis of $\alpha$-globin was observed only in cells transformed with a plasmid constructed with an antisense 68-mer that corresponded to the sequence from the cap site to the first exon (the cells were designated Oligo-A). Furthermore, it was sur- 
prising to us that most of our antisense transformants did not show coordinated decreases in levels of endogenous $c-m y c$ mRNA after induction by HMBA. These results raises the possibility that the globin synthesis may represent an independent program of differentiation that is uncoupled from the early decline in levels of $c$ $m y c$ transcripts and the subsequent reexpression of these transcripts which play a causal role in the differentiation of MEL cells.

\section{MATERIALS AND METHODS}

Cells and reagents. MEL cells were grown at $37^{\circ} \mathrm{C}$ in Dulbecco's modified Eagle medium (DMEM; GIBCO, Grand Island, NY) supplemented with 10\% fetal bovine serum (FBS; GIBCO), and $10 \mathrm{mM} \mathrm{N}$-2-hydroxyethylene-piperidine-N-2ethane sulfonic acid buffer (HEPES), penicillin $(100 \mathrm{U} / \mathrm{ml})$ and streptomycin $(100 \mu \mathrm{g} / \mathrm{ml})$. Differentiation of MEL cells and MEL transformants was induced by induction with $4 \mathrm{mM}$ HMBA in DMEM plus 10\% FBS for 3-4 days. Restriction enzymes, DNA polymerase 1 from $E$. coli (Klenow fragment), T4 ligase, T4 kinase and an oligolabelling kit were purchased from Takara Shuzo Inc., Kyoto. Mycophenolic acid, xanthine, hypoxanthine, aminopterine and thymidine were obtained from Sigma, St. Louis, MO. All other chemical reagents were purchased from Nakarai-Kagaku Inc., Tokyo.

Synthesis and purification of oligomers. Antisense or sense 68-base oligodeoxynucleotides (oligomer A), corresponding to the region from the cap site to the eleventh amino acid encoded by the mouse $\alpha$-globin gene (5'CCTTGATGTTGCTTTTGTCTTCCCCAGAGAGCACCATGGTTCTTCCTGAGTCTGCCAGAATCAGAAGT3'), and 11-mers that correšponded to the $3^{\prime}$-end region (5'ACTTCTGATTC 3 ') were synthesized on an automated solid-phase synthesizer (Applied Biosystems, Foster City, CA) by the standard phosphoramidite coupling method, and were purified by high-pressure liquid chromatography or by gel electrophoresis (10). Other antisense or sense 68-base oligodeoxynucleotides and their corresponding $3^{\prime}$ complementary 11 -mers (oligomers $\mathrm{B}, \mathrm{C}, \mathrm{D}, \mathrm{E}$, $\mathrm{F}$ in Fig. 1B) were designed and synthesized in the same manner.

Construction of plasmids. The strategy for all constructions involved cloning the gene for Ecogpt into pSVMdhfr and replacing the gene for dehydrofolate reductase with 68 mers from the gene for $\alpha$-globin, the gene for mouse major histocompatibility complex class I antigen, $\mathrm{H}-2 \mathrm{~K}^{\mathrm{b}}$, or the gene for xanthine-phosphoribosyl transferase from $E$. coli. Plasmids with the antisense and sense $\alpha$-globin 68-mer, pSVgpt68, contained the $\alpha$-globin sequences cloned in the antisense and sense orientations relative to a promoter from simian virus 40 (SV40) plus the selection marker, the gene for Ecogpt. 68-mer oligodeoxynucleotides were made double-stranded and bluntended with DNA polymerase I from $E$. coli (Klenow fragment), using the 11-mers as primers (see Fig. 1B). HindIII linkers were ligated to the double-stranded 68-mers. Plasmid
pSVdhfr (18) was digested with BglII and HindIII. The resulting fragment (containing one internal BamHI site) was purified electrophoretically, and BamHI linkers were added and then the fragment was treated with CIP (calf intestine alkaline phosphatase; Boehringer-Mannheim, Mannheim, Germany) to generate $\mathrm{pSV}-\mathrm{H}$. Antisense and sense 68 -meric sequences corresponding to the mouse $\alpha$-globin gene were inserted into the new BamHI site of pSV-H to generate pSV68. Antisense and sense plasmids pSVH- $2 \mathrm{~K}^{\mathrm{b}}$ carried the $\mathrm{H}-2 \mathrm{~K}^{\mathrm{b}}$ gene on a 5.0-kb NruI-EcoRI fragment in place of a 68-mer. Every sense and antisense construct was sequenced to check the cloned sequences and each was used for the transfection study.

Transfection. Cells were transfected with plasmid DNAs $(20 \mu \mathrm{g})$ by the standard protoplast-fusion method (28). Tissue-cultured MEL cells $\left(5 \times 10^{5} / \mathrm{ml}\right)$ and protoplasts $(5 \times$ $10^{8}$ ) were fused in $1.5 \mathrm{ml}$ of $50 \%$ polyethylene glycol (PEG) 1500 (Sigma) in serum-free DMEM and plated in 96-well dishes (Nunc, Roskilde, Denmark) at two densities, namely, $10^{4}$ cells/well and $10^{3}$ cells/well. Two days later, selection for the ability to grow in DMEM supplemented with mycophenolic acid $(25 \mu \mathrm{g} / \mathrm{ml})$, aminopterine, xanthine, hypoxanthine and thymidine was performed as described by Mulligan and Berg (23). Transformants resistant to a high concentration of mycophenolic acid $(110 \mu \mathrm{g} / \mathrm{ml})$ were obtained by continued cultivation in DMEM plus mycophenolic acid over a period of two months, during which time the concentration of mycophenolic acid was increased at two-week intervals. Control anti-

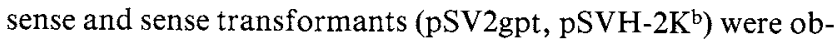
tained by cotransfection with pSV2gpt, as described elsewhere $(23,28)$. The same amplification protocol was used as described above. The identification of antisense transformants was carried out by use of the RNA dot blots of the established clones with an antisense RNA-specific probe and staining with benzidine (9).

Analysis of DNA and RNA. High-molecular-weight DNA was isolated and then digested with appropriate restriction enzymes. The digested samples were subjected to electrophoresis on $1 \%$ agarose gels which were then blotted onto nitrocellulose filters as described elsewhere (19). Total RNA was isolated by the guanidium isothiocyanate (GTC) method (1). Total RNA $(10 \mu \mathrm{g})$ for Northern blots was fractionated on $1.1 \%$ agarose formaldehyde denaturing gels and then transferred to nitrocellulose membranes (19). The probes used for analysis of DNA and RNA were prepared from singlestranded M13 viral DNA that contained a copy of a 68 -mer by use of T4 kinase and [ ${ }^{-32}$ P]-ATP $(>3,000 \mathrm{Ci} / \mathrm{mmol}$; Amersham Japan). For Northern blot analysis of transcripts of $c$ $m y c, 2.2-\mathrm{kb} B a m \mathrm{HI}$ fragments of human $c-m y c$ cDNA (33) and a mouse $\beta$-actin cDNA probe (33) were radiolabeled by the standard oligolabeling procedure (8). In order to estimate the relative amounts of antisense and sense transcripts, we cut up the filters used for the Northern blots after hybridization and measured the radioactivity of the bands.

Radiolabeling of cells and quantitation of globin synthesis. MEL cells and transformants, after induction for 2 days 
with HMBA, were incubated for up to $18 \mathrm{~h}$ in $10 \mathrm{ml}$ of leucine-free DMEM medium with $1 \mathrm{mCi}$ of $\mathrm{L}-\left[4,5-{ }^{3} \mathrm{H}\right]$-leucine (120-190 Ci/mol; Amersham Japan) or $250 \mu \mathrm{Ci}$ of $\mathrm{L}-\left[1-{ }^{14} \mathrm{C}\right]$ leucine ( $>300 \mathrm{mCi} / \mathrm{m}$ mol; Amersham Japan). Radiolabeled cells were harvested, washed with phosphate-buffered saline (PBS) and lysed with a solution of $10 \mathrm{mM}$ Tris (pH 7.4), 0.1 $\mathrm{M} \mathrm{NaCl}, 1 \% \mathrm{Na}$-deoxycholate, $1 \%$ Triton X-100, $0.1 \%$ SDS and $1 \mathrm{mM}$ phenylmethyl sulfonylfluoride (PMSF). After centrifugation at $100,000 \times \mathrm{g}$ for $45 \mathrm{~min}$, the supernatant was applied to a haptoglobin-affinity column $(0.9 \mathrm{~cm}$ i.d. $\times 15 \mathrm{~cm} ; 1-$ $\mathrm{ml}$ fractions) which had been equilibrated with $5 \%$ formic acid. Conjugation of the Sepharose 4B-CL (Pharmacia LKB, Uppsala, Sweden) with haptoglobin for the affinity column and the purification of globin species from the column were carried out by the procedures described by Tsapis et al. (30). Quantitative analysis of the synthesis of globin chains was performed by column chromatography $(0.4 \mathrm{~cm}$ i.d. $\times 29 \mathrm{~cm} ; 200-$ $\mu 1$ fractions) on CM-cellulose in $8 \mathrm{M}$ urea (31).

Staining techniques. Cells were placed on glass coverslips $\left(15 \times 15 \mathrm{~mm}^{2}\right)$, washed gently with PBS and then fixed for 20 min with $3.7 \%$ formaldehyde. After fixation, cells were stained with either 5\% Giemsa (GIBCO) for $10 \mathrm{~min}$ or with two drops of a mixture of $0.4 \%$ benzidine base and $2 \%$ hydrogen peroxide in $12 \%$ acetic acid in culture medium (approximately $200 \mu 1$ ) for $10 \mathrm{~min}$.

\section{RESULTS}

Long-term transfection with antisense plasmids. Each pSVgpt68 plasmid contained the SV40 promoter linked to a sequence of 68 base pairs in the antisense orientation or in the sense orientation (see Fig. 1A). Six antisense constructs, with DNA complementary to 68mers, corresponded to the following regions of the mouse $\alpha$-globin gene (Fig. 1B): oligomer A covered the sequence from the cap site to the sequence that encoded the eleventh amino acid; oligomer B covered the sequence from the first intron to the second exon which contains the 3 '-end splice junction; oligomer $\mathrm{C}$ covered the sequence from the second exon to the second intron which contains the 5 -end splice junction; oligomer D covered the sequence from the second intron to the third exon which contains the 3 '-end splice junction; oligomer $\mathrm{E}$ contained part of the coding sequence of exon 3 ; and oligomer $\mathrm{F}$ covered the $3^{\prime}$ untranslated region of the $\alpha$-globin gene. Each recombinant antisense $\alpha$-globin construct was introduced into cells by protoplast fusion to determine whether its expression could reduce the rate of translation of the globin mRNAs. The frequency of transfection was $1-5 \times 10^{-7}$ after the protoplast fusion (28). We initially identified the antisense mixed transformed clones (see Table I; Oligo-A, -B, -C, -D, $-E,-F)$ by primary screening, using benzidine staining and subsequent dot hybridization with a probe specific for antisense RNA, as described in MATERIALS AND
Methods. Then we recloned and established five antisense transformed clones (the AG clones) from the antisense mixed transformant Oligo-A by the limiting-dilution method (see Table I).

Amplification of antisense transcripts. To increase the levels of RNA transcripts, elevated concentrations of mycophenolic acid were used to select the cells with elevated levels of the $\alpha$-globin 68 -mers, as described previously (33-35). Resistance to mycophenolic acid (MA) was gradually increased by successive rounds of selection with doubling of the concentration of MA after each round. This procedure resulted in cells that contained higher levels of antisense transcripts. Analysis of one-week cultivation and two-month cultivation of antisense transformants revealed that gradually increasing amounts of transcripts were generated. The clone cultivated for two months exhibited a significantly higher level of expression of antisense transcripts as compared with a clone cultivated for only one week (Fig. 2B, lanes 10, 11, 14 and 15). The amplification of the antisense RNA gene may be associated with the resistance to higher concentrations of MA. Examination of genomic DNA isolated from antisense transformants, parental MEL cells, and control pSV2gpt transformants suggested that the amplification of antisense DNA to approximately 5 to 25 copies per genome is responsible for the higher levels of Ecogpt (data not shown). The amplification of previously integrated antisense $\alpha$-globin DNA only occurred after a prolonged selection period with gradually increasing concentrations of MA. The endogenous levels of $\alpha$-globin RNA from antisense transformants, after induction with HMBA, were nearly identical except in the case of a few transformants (Fig. 2A).

Antisense RNA inhibits the production of $\alpha$-globin. Transformants with antisense $\alpha$-globin 68 -mers were incubated with $\left[{ }^{3} \mathrm{H}\right]$-leucine for $18 \mathrm{~h}$ for estimation of the production of $\alpha$-globin. Sense $\alpha$-globin clones, cells transformed with control pSV2gpt, and MEL cells incorporated $50 \%$ to $60 \%$ of the added leucine. The rates of incorporation of leucine into the various cells were almost identical. We used column chromatography to separate the $\alpha$ - and $\beta$-globin chains as described by Tsapis et al. $(30,31)$ and Mankinen et al. $(20)$, instead of using monospecific antibodies against each species of mouse globin chain. The peaks of CM cellulose column chromatography corresponding to adult $\alpha$ - and $\beta$-globins were observed in the analysis of MEL parental cells and pSV2gpt transformants after induction with HMBA. The ratio of the areas of the peaks that corresponded to $\alpha$-and $\beta$-globins was about $1: 2$ in the case of MEL cells after induction with HMBA (Fig. 3, Panels A, B). The ratio was estimated after correction for the frequency of incorporation and the number of leucine residues in each component. In the absence of in- 
K. Yokoyama et al.
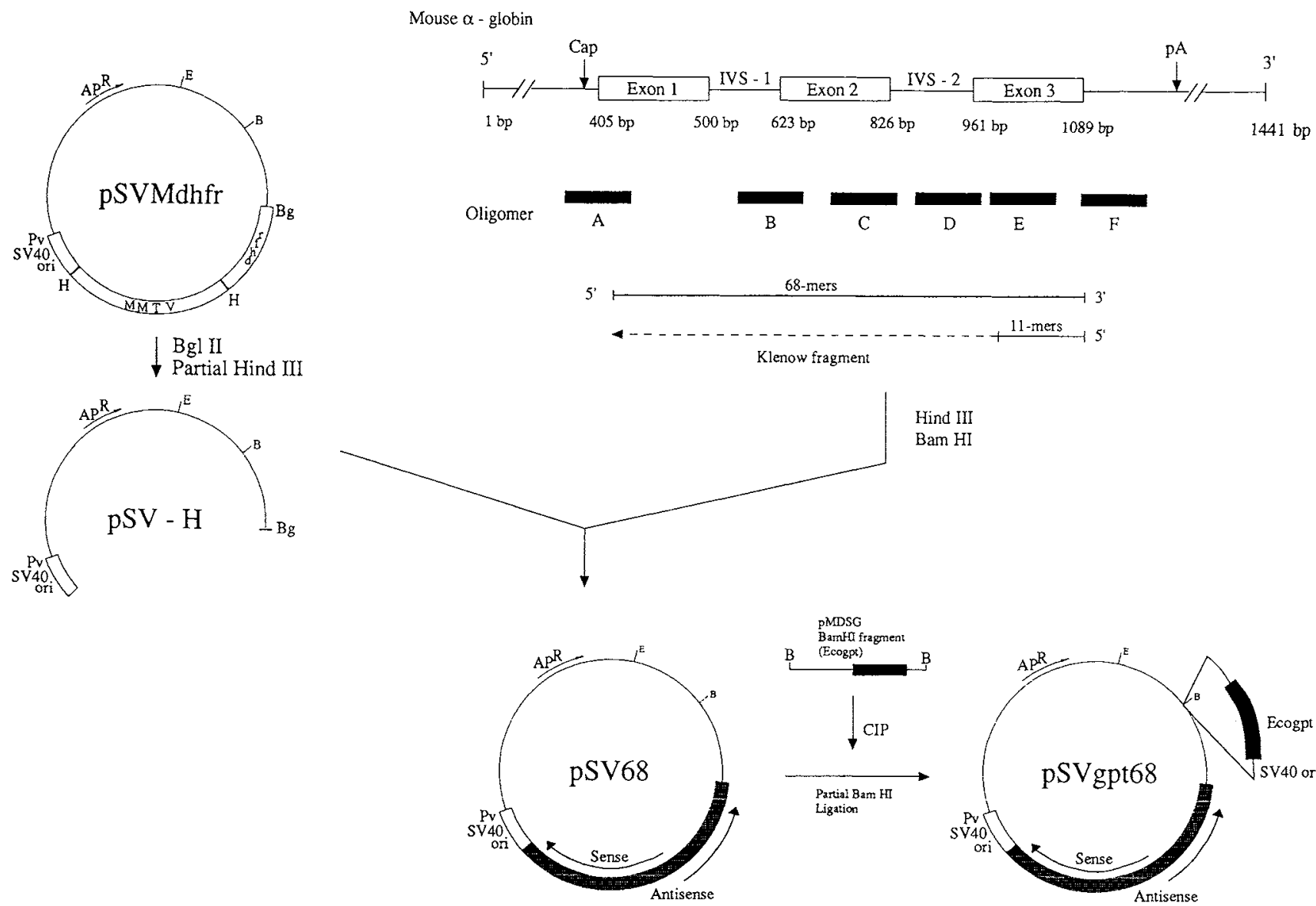

Fig. 1A.

Oligomer A : 5' -CCPTGATGTTGCTTTTGTCTTCCCCAGAGAGCACCATGGTTCTMCCTGAGTCTGCCAGAATCAGAAGT-3' $: 5^{\prime}$-ACTTCTGATTC-3' ( nt +1- +68)

$\begin{aligned} \text { Oligomer B } & : 5^{\prime} \text {-AAACATCCTGGGAGAAGGAGAGAAGAGAAGTTGAGGTCACAGAAAAGCATAGTTAGTTGCTGCCCACT-3' } \\ & \left.: 5^{\prime} \text {-AGTGGGCAGCT-3'(nt }+180-+249\right)\end{aligned}$

Oligomer $\mathrm{C}: 5^{\prime}$-ATACCTTGAACTTGACGGGATCCACACGCAGCTTGTGGGCATGCAGGTCGCTCAGAGCAGACAAGGCA-3' $: 5^{\prime}$-TGCCTTGTCTG-3' ( nt +389- +450)

O1igomer D :5' -GGCTCAGGAGCTGCGGAGACAAAGTGGACACCCTGATGCCTCTGCTCCCCTTCCTGGGACCACTATGT-3' $: 5^{\prime}$ - ACATAGTGGTC-3' ( nt +521- +600)

Oligomer $E: 5^{\prime}$-AGCACGGTGCTCACAGAGGCAAGGAATTTGTCCAGAGAGGCATGTACCGCGGGGGTGAAATCGGCAGG-3' $: 5^{\prime}-$ CCTGCCGATTT $-3 '(\mathrm{nt}+631-+710)$

Oligomer $F$ : 5' -TTTATTCAAAGACCAAGAGGTACAGGTGCAAGGGAGAGAAGAAGGGCATGGCCAGAAGGCAAGCCCCG-3' : $5^{\prime}$-CGGGGCTTGCC-3' ( nt +740 - +818)

Fig. 1B.

Fig. 1. Construction of antisense and sense pSVgpt68 plasmids and antisense oligomeric sequences.

(A) Construction of plasmids is described in MATERIALS AND MeTHODS. The drawing illustrates the genomic organization of the mouse $\alpha$-globin gene. Boxes represent exons and lines represent flanking and intervening sequences (introns). The black box in the BamHI fragment of pMDSG represents the coding region of the gene for Ecogpt. The positions of synthesized antisense 68-mers that correspond to various regions of the mouse $\alpha$-globin gene are indicated by the shaded boxes (A, B, C, D, E, F).

(B) The antisense oligomers corresponding to the mouse $\alpha$-globin gene, as indicated in Fig. 1A. Each 68 -meric and 11-meric nucleotide sequence is represented. +1 indicates the cap site of the $\alpha$-globin gene. 


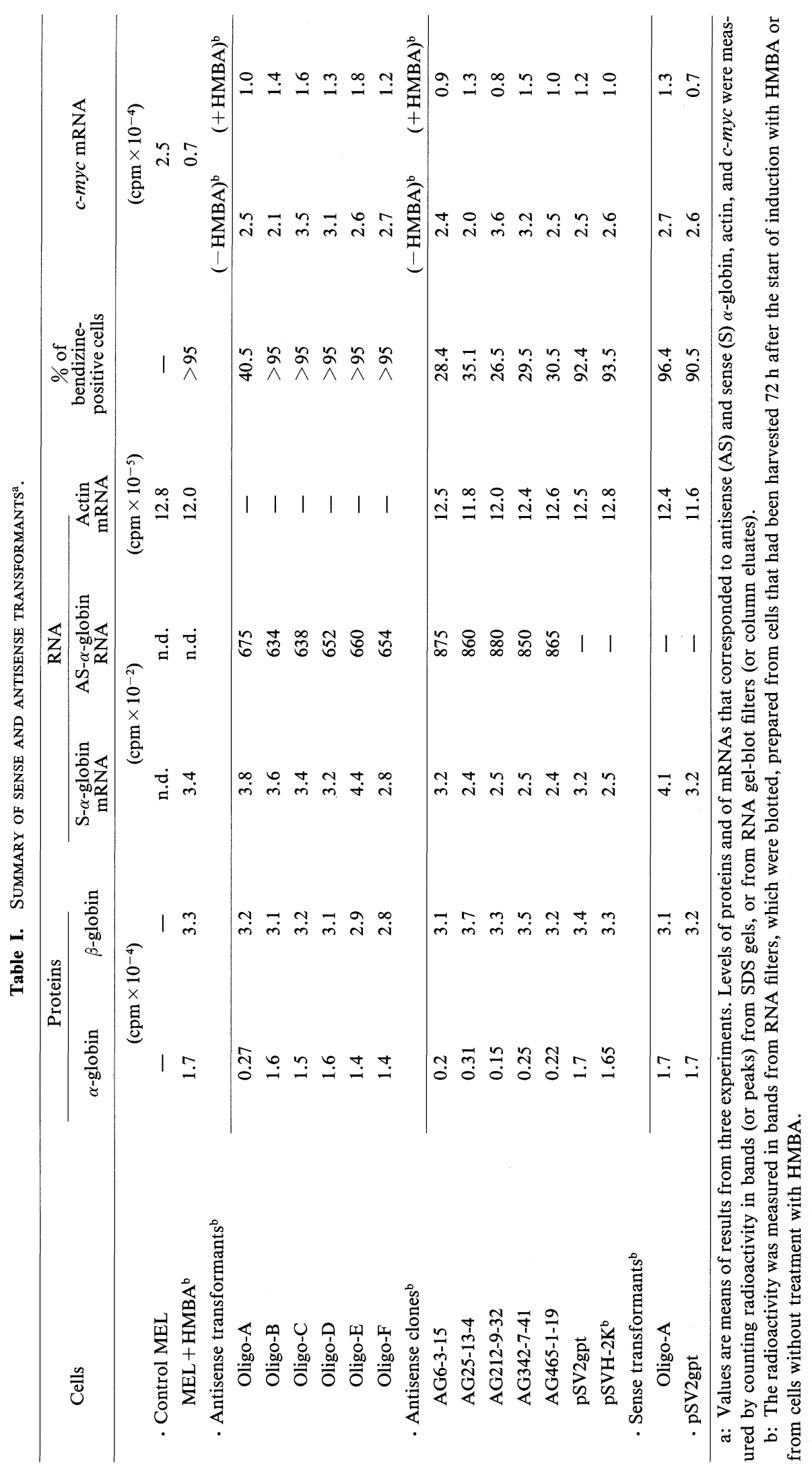


duction by HMBA, neither $\alpha$ - nor $\beta$-globin was detected in the case of MEL and pSV2gpt-transformed cells (Fig. 3, Panel A). About $80 \%$ to $90 \%$ inhibition of the synthesis of $\alpha$-globin was observed in the cells transformed with an antisense 68-mer plasmid (oligomer A; AG series of transformed clones; Fig. 3, panels D, E, F, G, $\mathrm{H}$ ), as judged by the relative radioactivity associated with the peaks of $\alpha$ - and $\beta$-globin after the column chromatography on CM-cellulose. Other antisense 68-mer plasmids (oligomers B, C, D, E and F) were not associated with a reduction in the production of $\alpha$-globin after induction with HMBA (Fig. 3, panels I, J, K, L and $\mathrm{M}$ ). These studies suggest that only the antisense 5'end leader sequence can effectively inhibit the translation of the $\alpha$-globin gene. However, no reduction in the production of $\beta$-globin was observed despite the fact that the extent of sequence homology between the capsite sequences of the gene for $\alpha$-and $\beta$-globin is between $40 \%$ and $50 \%$. Thus, the observed antisense inhibition appears to be sequence-specific.

Expression of c-myc in antisense $\alpha$-globin transformants. Several groups have reported that decreased expression of $c-m y c$ is a prerequisite for the triggering of the differentiation of erythroleukemia cells $(2,4,15,16$, 27). The expression of endogenous c-myc RNA in cells transfected with antisense and sense 68-mer plasmids was analyzed (Fig. 4). There were no significant variations when cells were harvested $72 \mathrm{~h}$ after the start of induction with HMBA (see Table I). To examine the differentiation program of these cells in greater detail, we analyzed the kinetics of accumulation of committed cells and the levels of $c-m y c$ RNA after treatment with

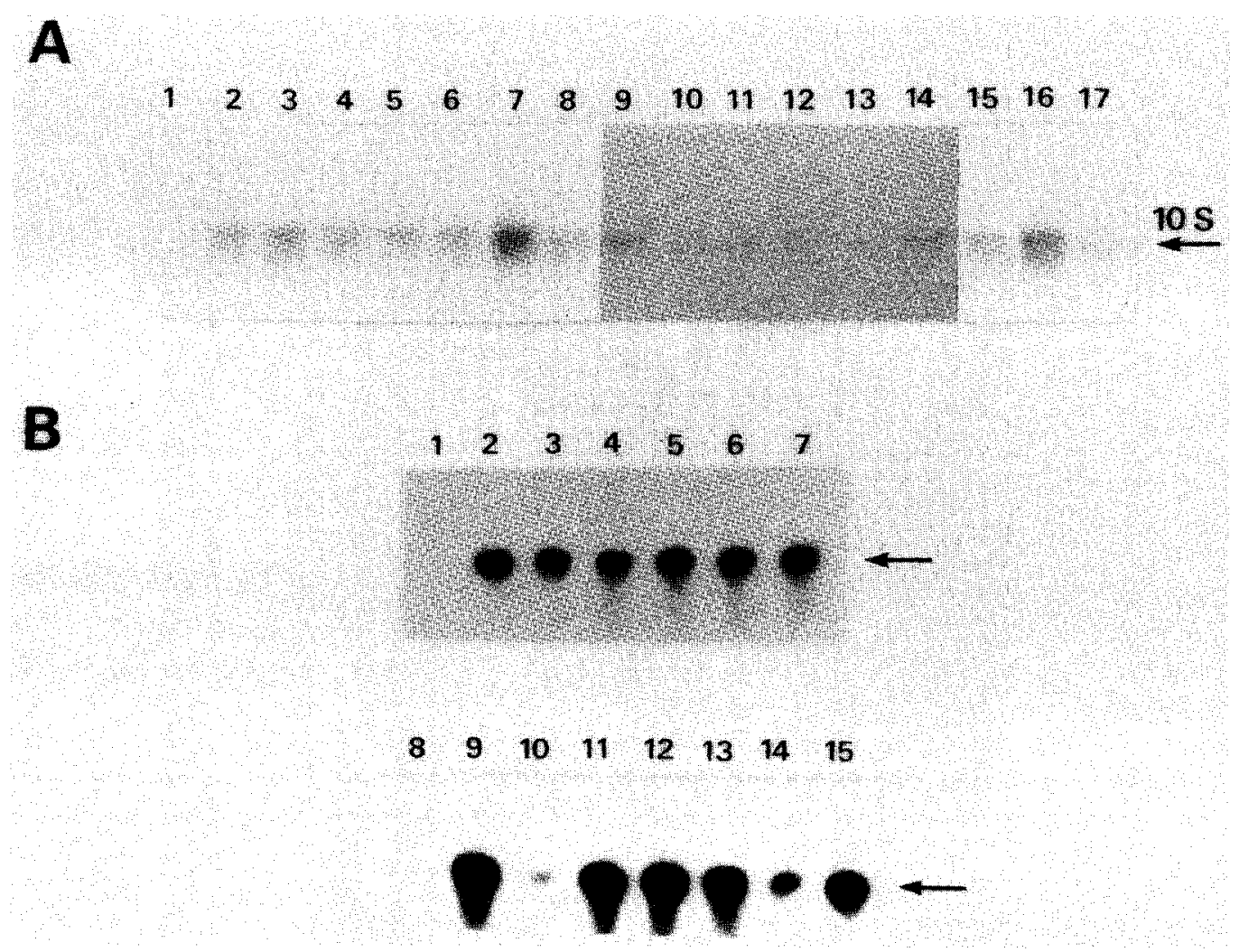

Fig. 2. Northern blot analysis of total RNA prepared from MEL cells and transformants after transfection with expression vectors that contained antisense $\alpha$-globin 68-mers. The probes used were [32P]-labeled sense $\alpha$-globin M13 cDNA (panel A) and antisense $\alpha$-globin M13 cDNA (panel B). (A) Lane 1, MEL cells; lane 2, MEL cells induced by treatment with HMBA for 2 days; lane 3, antisense transformant (Oligo-A); lane 4, antisense transformant (Oligo-B); lane 5, antisense transformant (Oligo-C); lane 6, antisense transformant (Oligo-D); lane 7, antisense transformant (Oligo-E); lane 8, antisense transformant (Oligo-F); lane 9, AG6-3-15; lane 10, AG25-13-4; lane 11, AG212-9-32; lane 12, AG3427-41; lane 13, AG465-1-19; lane 14, antisense pSV2gpt transformant induced by treatment with HMBA; lane 15, antisense pSVH-2K $\mathrm{K}^{\mathrm{b}}$ transformant induced by treatment with HMBA; lane 16, sense pSV2gpt transformant induced by treatment with HMBA; lane 17, sense pSVH-2K transformant induced by treatment with HMBA. (B) Lane 1, MEL cells; lane 2, antisense transformant (Oligo-A); lane 3, antisense transformant (Oligo-B); lane 4, antisense transformant (Oligo-C); lane 5, antisense transformant (Oligo-D); lane 6, antisense transformant (Oligo-E); lane 7, antisense transformant (Oligo-F); lane 8, MEL cells induced by treatment with HMBA; lane 9, AG6-3-15; lane 10, AG25-13-4 (1 week); lane 11, AG25-13-4 (2 months); lane 12, AG212-9-32; lane 13, AG342-7-41; lane 14, AG465-1-19 (1 week); lane 15; AG465-1-19 (2 months). Arrows indicate the endogenous $\alpha$-globin transcript (panel A) and the antisense transcript (panel B). 
HMBA. The $\beta$-actin DNA probe was used as a control of Northern hybridization to ensure the equal amounts of RNA in each lane (Fig. 4E). In cultures of MEL cells and pSV2gpt transformants, an increase in the percentage of committed cells was first detected between $18 \mathrm{~h}$ and $24 \mathrm{~h}$ of the start of treatment with HMBA (Fig. 4A, B). With increasing duration of exposure to HMBA, there was a gradual increase in the percentage of committed cells, such that by $72-96 \mathrm{~h}$ nearly all of the cells were committed. The kinetics of accumulation of committed MEL cells reported here are similar to those found by other investigators $(9,11,26)$. It was surprising to us that most of the antisense transformants did not show an initial decline in endogenous levels of $c$ myc mRNA (Fig. 4C, D). Both antisense transformants (Oligo-B) that harbored Oligomer B and AG212-9-32 transformed clone, for example, did not show any early decline in the level of the transcript of the $c-m y c$ gene. We cannot adequately explain why antisense transformants with 68-mer DNAs that included Oligo-B and AG212-9-32 exhibited altered expression of c-myc mRNA when treated with inducer, while there was no
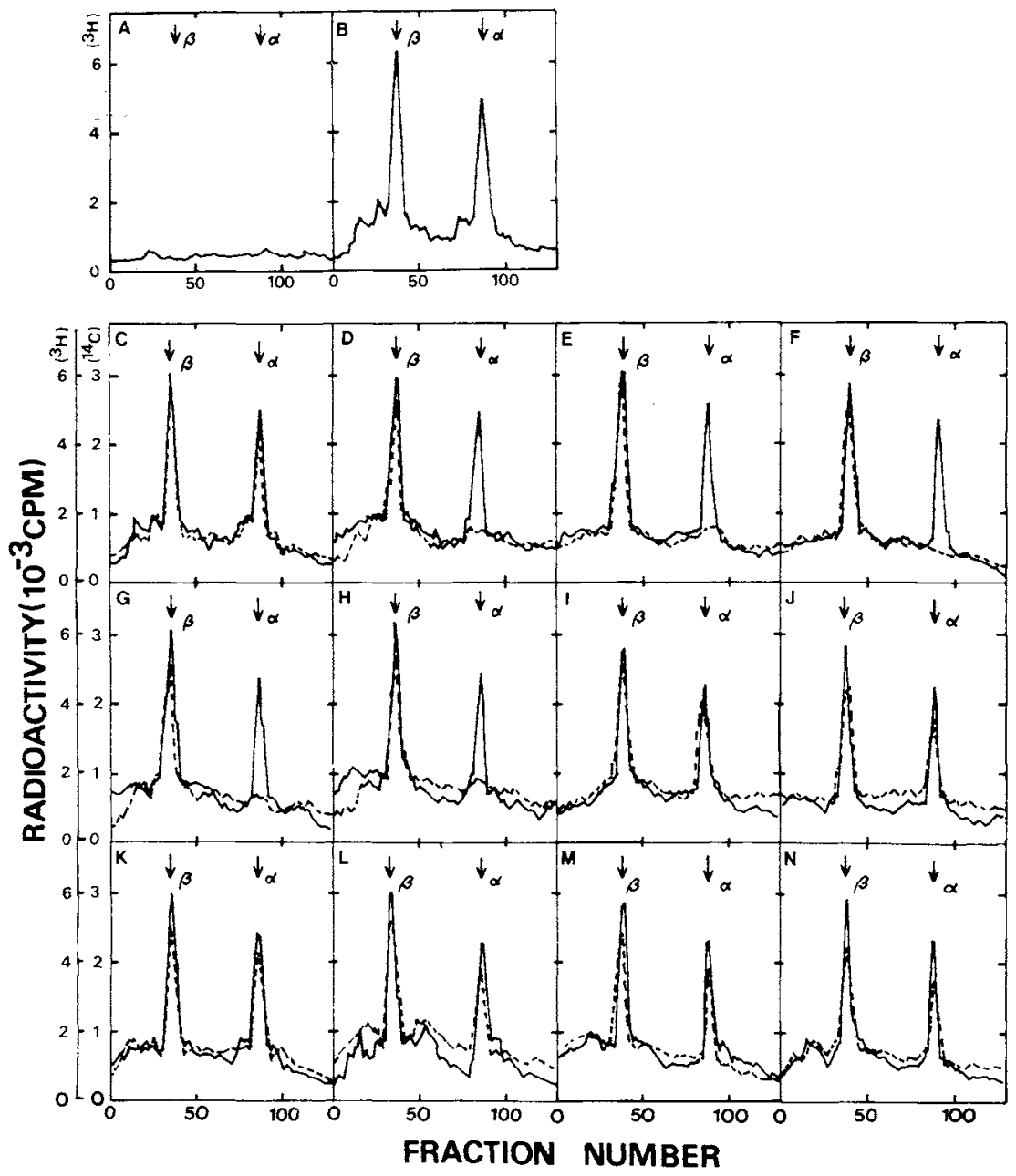

Fig. 3. Separation by column chromatography on CM-cellulose of $\left[{ }^{3} \mathrm{H}\right]-$ and/or $\left[{ }^{14} \mathrm{C}\right]$-labeled globin chains synthesized in MEL cells and their transformants before and after induction of cells with HMBA. $5 \times 10^{7}$ cells were radiolabeled with $\left[{ }^{3} \mathrm{H}\right]-$ or $\left[{ }^{14} \mathrm{C}\right]-1$ eucine and about $1 \%$ of the total incorporated radioactivity was eluted from the haptoglobin-affinity column. The elution followed the method of Tsapis $e t$ al. (30, 31). Fractions $(200 \mu \mathrm{l})$ were collected at a flow rate $4 \mathrm{ml} / \mathrm{h}$ and the radioactivity of aliquots $(20 \mu \mathrm{l})$ was measured. Arrows from left to right in each panel indicate the positions of elution of $\beta$ - and $\alpha$-globin, respectively. Panel A, $\left[{ }^{3} \mathrm{H}\right]$-labeled globin in MEL cells; panel B, $\left[{ }^{3} \mathrm{H}\right]$-labeled globin in MEL cells induced by treatment with HMBA; panel C, antisense transformant pSV2gpt; panel D, AG6-3-15; panel E, AG25-13-4; panel F, AG212-932; panel G, AG342-7-41; panel H, AG465-1-19; panel I, antisense transformant (Oligo-B); panel J, antisense transformant (Oligo-C); panel K, antisense transformant (Oligo-D); panel $\mathrm{L}$, antisense transformant (Oligo-E); panel $\mathrm{M}$, antisense transformant (Oligo-F); panel $\mathrm{N}$, antisense pSVH- $2 \mathrm{~K}^{\mathrm{b}}$. The ${ }^{\left[{ }^{14} \mathrm{C}\right]-l e u c i n e-l a b e l e d ~ f r a c t i o n ~(s o l i d ~ l i n e), ~ a s ~ a n ~ i n t e r n a l ~ c o n t r o l, ~ f r o m ~ t h e ~ h a p t o g l o b i n-a f f i n i t y ~ c o l u m n ~(M E L ~ c e l l s ~ i n d u c e d ~ b y ~}$ treatment with HMBA; $3 \times 10^{5} \mathrm{cpm}$ ), was mixed with the $\left[{ }^{3} \mathrm{H}\right]$-leucine-labeled fraction (dotted line) from the haptoglobin-affinity column $\left(3 \times 10^{5}\right.$ $\mathrm{cpm}$ ) and applied to the column of CM-cellulose. 
apparent difference in the levels of antisense transcripts of the $\alpha$-globin gene within these clones or in the numbers of copies of integrated antisense sequences (data not shown). A similar phenomenon was found for more than twenty clones from twenty-four transformants including Oligo-A, -B, -C, -F, AG6-3-15, AG25-13-4, AG212-9-32 and AG465-1-19.

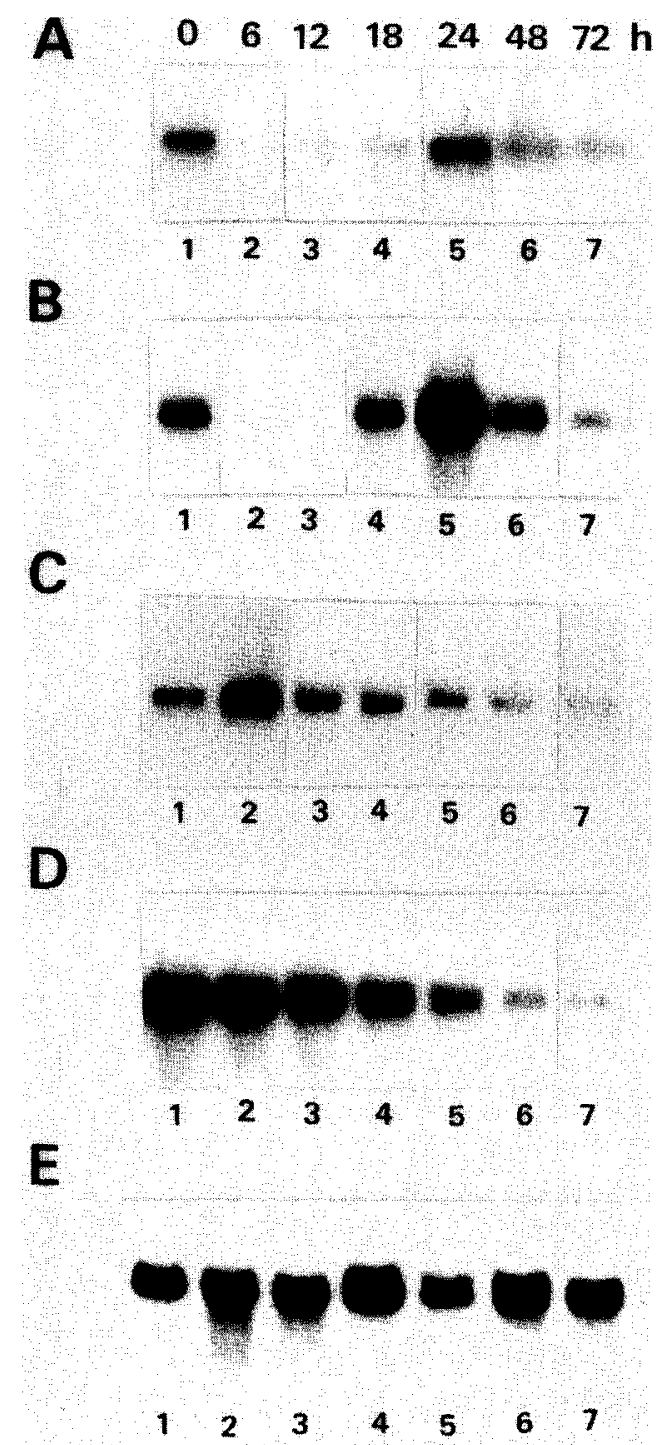

Fig. 4. Kinetics of changes in levels of endogenous c-myc transcripts in MEL cells after induction by treatment with HMBA (panel $A$ ), in the sense transformant pSV2gpt (panel B), in antisense transformant Oligo-B (panel $C$ ), in the antisense transformed clone AG212-9. 32 (panel D), and the $\beta$-actin transcript, as a control, in MEL cells after treatment with HMBA (panel E) were monitored. Logarithmically growing cells were treated with $4 \mathrm{mM}$ HMBA for the times indicated. The same amounts of total RNA ( $40 \mu \mathrm{g})$ were subjected to the Northern blots and was hybridized as described in MATERIALS AND METHODS.

\section{DISCUSSION}

Recent studies have shown that the introduction of antisense RNA can result in a specific inhibition of the expression of cellular genes $(3,13,33,34,35)$. We utilized an antisense RNA approach to inhibit the expression of the $\alpha$-globin gene that is induced by HMBA. The level of the antisense $\alpha$-globin 68-mer DNA in the antisense Oligo-A transformants and their AG-clones was about 5 to 25 copies per cell. We calculated that the minimum ratio of antisense DNA to endogenous DNA required for inhibition of production of $\alpha$-globin was 1 to 5-25 (Fig. 2A, B) on the basis of the radioactivity of Southern hybridization filters and the molar ratio of the DNAs; with these relative levels, there was about 5- to 10 -fold more of the antisense $\alpha$-globin 5 -end oligomer RNA than of the endogenous $\alpha$-globin RNA, as estimated from the specific radioactivity of the Northern hybridization filters and the molar ratio of the RNAs. The steady-state level of $\alpha$-globin in the antisense Oligo-A transformants and their clones was reduced by more than $80-90 \%$ per cell as compared to that in MEL cells (Table I). The control experiments, in which cells were transfected with antisense $\mathrm{H}-2 \mathrm{~K}^{\mathrm{b}}\left(\mathrm{pSVH}-2 \mathrm{~K}^{\mathrm{b}}\right)$, and with the antisense pSV2gpt plasmid were associated with no significant reduction in the synthesis of $\alpha$-globin (Fig. 4, Table I). No reduction in the rate of synthesis of $\beta$ globin was observed at the translational level even though there is approximately 50\% homology in terms of nucleotide sequence between the cap sites of the genes for $\alpha$-and $\beta$-globin. These results indicate that the inhibition is highly sequence-specific and that only one 68 -nucleotide $5^{\prime}$-end oligomer (oligomer A), which corresponds to the region from the cap site to the site of translation of initiation, of the gene for $\alpha$-globin, was able to suppress the inducible expression of this gene. Melton previously reported that an antisense RNA complementary to the $5^{\prime}$ untranslated region of the $\beta$-globin mRNA blocked translation and, moreover, that antisense RNAs complementary to only the $3^{\prime}$ part of the globin mRNA were unable to block translation (22). By contrast, Strickland et al. presented results to indicate that an antisense RNA that corresponded to the $3^{\prime}$-terminal region prevented the translation of the mRNA for tissue plasminogen activator (t-PA), polyadenylation, and the destabilization of the mRNA, these processes that normally occur in concert during the maturation of mouse oocytes (29). Although we do not know which regions of mRNA, with respect to the construction of antisense RNA, are associated with the most effective inhibition of translation of the mRNA, a conclusion of practical value from the present study is that antisense RNA that covers the initiation codon and the 5 -untranslated cap sites should be used for translation-blocking experiments. Neither the antisense RNA complementary to 
only the cap site nor only to the translation initiation codons can block the translation of $\alpha$-globin gene efficiently (data not shown). It seems likely that the $5^{\prime}$ region of the message, where ribosomes bind and initiate translation, must be covered by antisense RNA if translation is to be blocked (22).

Induction of the differentiation of MEL cells is associated with a dramatic change in the expression of $c-m y c$ mRNA (16). This change may be important in terms of the role of $c$-myc protein in commitment, as a determinant of the differentiation. The introduction of an exogenous $c$-myc gene affects the commitment process (4, $15,22,26$ ), but the crucial aspects of its function have not been clearly documented. The biphasic pattern of expression of the $c-m y c$ gene, observed in several systems of differentiating cells including MEL cells, supports the hypothesis that a transient reduction in levels of $c$-myc RNA may be necessary for the irreversible withdrawal from the cell cycle $(6,7,14,36)$. The proliferation and differentiation of cells are considered to be coupled but mutually exclusive. This hypothesis is based on the observation that cessation of proliferation is usually associated with terminal differentiation and that many types of terminally differentiated cell are unable to re-enter the cell cycle when challenged with mitogens (24). Kume et al. (15) reported that $c$-myc is directly involved in commitment and that the late decline in levels of $c$-myc mRNA is essential for the commitment process, rather than the early decline in such levels. However, we observed that most antisense transformed AG clones including AG212-9-32 were able to commit to the differentiation program, as judged from the results of staining with bendizine (25-40\%), although the synthesis of the $\alpha$-globin chain was completely blocked (Fig. 4D). Some of antisense transformants including Oligo-B were also differentiated (Fig. 4C and Table I). In these antisense transfected clones, the levels of the $c$ $m y c$ transcript are maintained during the process of differentiation of MEL cells (Fig. 4C, D). This altered expression of $c$-myc RNA was not due to the sequence specific because most antisense transformants which were generated by the plasmids harbored the different DNA sequence region of $\alpha$-globin gene. We do not know the exact mechanism for such increments in levels of $c-m y c$ mRNA. We speculate this effect might be due to the direct or indirect mechanism by introduction of antisense RNA.

Our data suggest that the coordinate early decline or transient increase in levels of endogenous $c$-myc RNA during the first hours of chemical induction may not be required for terminal differentiation. However, we cannot rule out the possibility that the late decline in levels of $c-m y c$ transcripts ( $48 \mathrm{~h}$ to $72 \mathrm{~h}$ after exposure with HMBA) is important for the commitment of MEL cell differentiation, which was suggested by Kume et al.
(15). Thus, we propose the hypothesis that the program for production of $\alpha$-globin and the decline in levels of $c$ myc transcripts during the early phases of differentiation are usually unrelated events during the differentiation of MEL cells.

Acknowledgements. We wish to thank Dr. G. Ringold for generously providing plasmids pSVMdhfr and pMDSG. We are grateful to Ms. K. Oka, Ms. S. Tanimoto and Ms. M. Nifuku for preparing the manuscript. This work was supported by the Grants from the Japanese Science and Technology Agency (to K.Y. and G.G.) and by a grant from the National Cancer Institute, USA (CA 46676 to K.N.).

\section{REFERENCES}

1. Chirgwin, J., Aeybyle, A., McDonald, R., and Rutter, W. (1979). Isolation of biologically active ribonucleic acid from sources enriched in ribonuclease. Biochemistry, 18: 5294-5299.

2. Cole, M.D. (1986). The myc oncogene: its role in transformation and differentiation. Ann. Rev. Genet., 20: 361-384.

3. Coleman, J., Green, P.J., and Inouye, M. (1984). The use of RNAs complementary to specific mRNAs to regulate the expression of individual bacterial genes. Cell, 37: 429-436.

4. Coppola, J.A. and Cole, M.D. (1986). Constitutive $c-m y c$ oncogene expression blocks mouse erythroleukemia cell differentiation but not commitment. Nature (London), 320: 760-763.

5. Dmitrovsky, E., Michael Kuehl, W., Hollis, G.F., Kirsch, I.R., BENDER, T.P., and SEgal, S. (1986). Expression of a transfected human $c-m y c$ oncogene inhibits differentiation of a mouse erythroleukaemia cell line. Nature (London), 322: 748750.

6. Dony, C., Kessel, M., and Gruss, P. (1985). Post-transcriptional control of $m y c$ and $p 53$ expression during differentiation of the embryonal carcinoma cell line F9. Nature (London), 317: 636-639.

7. Endo, T. and Nadal-Ginard, B. (1986). Transcriptional and post transcriptional control of $c-m y c$ during myogenesis: its mRNA remains inducible in differentiated cells and does not suppress the differentiated phenotype. Mol. Cell. Bio., 6: 14121421.

8. Feinberg, A.P. and Vogelstein, B. (1983). A technique for radiolabeling DNA restriction endonuclease fragments to higher specific activity. Anal. Biochem., 132: 6-13.

9. Fibach, E., Reuben, R.C., Rifinind, R.A., and Marks, P.A. (1977). Effect of hexamethylene bisacetamide on the commitment to differentiation of murine erythroleukemia cells. Cancer Res., 37: 440-444.

10. GaIT, M.J. (1984). Oligonucleotide Synthesis. IRL Press, Oxford.

11. Ganguly, S. and Skoultchi, A.I. (1985). Absolute rates of globin gene transcription and mRNA formation during differentiation of cultured mouse erythroleukemia cells. J. Biol. Chem., 260: 12167-12173.

12. Gusella, J., Geller, R., Clarke, B., Weeks, V., and Housman, D. (1976). Commitment to erythroid differentiation by Friend erythroleukemia cells: a stockastic analysis. Cell, 9: 221-229.

13. Izant, J.G. and Weintraub, H. (1984). Inhibition of thymidine kinase gene expression by anti-sense RNA: A molecular approach to genetic analysis. Cell, 36: 1007-1015.

14. Kelly, K., Cochman, B.H., Stiles, C.D., and Leder, P. 
(1983). Cell-specific regulation of the $c-m y c$ gene by lymphocyte mitogens and platelet-derived growth factor. Cell, 35: 603610.

15. Kume, T.U., Takada, S., and Obinata, M. (1988). Probability that the commitment of murine erythroleukemia cell differentiation is determined by the c-myc level. J. Mol. Biol., 202: 779786.

16. Lachman, H.M. and Skoultchi, A.I. (1984). Expression of $c-m y c$ changes during differentiation of mouse erythroleukemia cells. Nature (London), 310: 592-594.

17. Lachman, H.M., Cheng, G., and Skoultchi, A.I. (1986). Transfection of mouse erythroleukemia cells with myc sequences changes the rate of induced commitment to differentiate. Proc. Natl. Acad. Sci. USA, 83: 6480-6484.

18. Lee, F., Mulligan, R., Berg, P., and Ringold, G. (1981). Glucocorticoids regulate expression of dihydrofolate reductase cDNA in mouse mammary tumor virus chimaeric plasmids. $\mathrm{Na}$ ture (London), 294: 228-232.

19. Maniatis, T., Fritsch, E.F., and Sambrook, J. (1982). Molecular cloning. A laboratory manual, Cold Spring Harbor Laboratory, Cold Spring Harbor, N.Y.

20. Mankinen, M.W., Milstein, J.B., and Kon, H. (1972). Specificity of interaction of haptoglobin with mammalian hemoglobin. Biochemistry, 11: 3851-3860.

21. MARKs, P.A. and Rifkind, R.A. (1978). Erythroleukemic differentiation. Ann. Rev. Biochem., 47: 419-448.

22. Melton, D.A. (1985). Injected anti-sense RNAs specifically block messenger RNA translation in vivo. Proc. Natl. Acad. Sci. USA, 82: 144-148.

23. Mulligan, R.C. and Berg, P. (1981). Selection for animal cells that express the Escherichia coli gene coding for xanthineguanine phosphoribosyltransferase. Prol. Natl. Acad. Sci. USA, 78: $2072-2076$

24. Nguyen, H.T., Medford, R.M., and Nadal-Ginard, B. (1983). Reversibility of mouse differentiation in the absence of commitment: Analysis of a myogenic cell line temperature-sensitive for commitment. Cell, 34: 281-293.

25. NishIOKA, Y. and LEDER, P. (1979). The complete sequence of a chromosomal mouse $\alpha$-globin gene reveals elements conserved throughout vertebrate evolution. Cell, 18: 875-882.

26. ProchownIK, E.V. and KuKowsKa, J. (1986). Deregulated expression of $c-m y c$ by murine erythroleukaemia cells prevents differentiation. Nature (London), 322: 848-850.
27. Ramsay, R.G., Ikeda, K., Rifkind, R.A., and Marks, P.A. (1986). Changes in gene expression associated with induced differentiation of erythroleukemia: Protooncogenes, globin genes and cell division. Proc. Natl. Acad. Sci. USA, 83: 68496853.

28. SANDri-Goidin, R.M., Golin, A.L., LeVIN, M., and Glorioso, J.C. (1981). High-frequency transfer of cloned herpes simplex virus type I sequences to mammalian cells by protoplast fusion. Mol. Cell Biol., 1: 743-752.

29. Strickiand, S., Huarte, J., Belin, D., Vassalli, A., Rickies, R.J., and VASSALLI, J.D. (1988). Antisense RNA directed against the 3 -noncoding region prevents dormant mRNA activation in mouse oocytes. Science, 241: 680-684.

30. Tsapis, A., Pogard, M., Alfsen, A., and Mihaeslo, C. (1976). Binding of human hemoglobin and its polypeptide chains with haptoglobin coupled to an agarose matrix. Eur. J. Biochem., 64: 369-372.

31. Tsapis, A., Hinard, N., Testa, U., Dubart, A., VAINCHENKeR, W., RoUYer-Fessard, P., BEUZARD, Y., and RosA, J. (1980). Globin-chain affinity chromotography on Sepharose-haptoglobin: a new method of study of hemoglobin synthesis in reticulocytes, in bone marrow and in colonies of erythroid precursors. Eur. J. Biochem., 112: 513-519.

32. Thomas, S. and Axelrad, A.A. (1968). A quantitative spleen colony assay method for tumor cells induced by Friend leukemia virus infection in mice. Cancer Res., 28: 2105-2114.

33. Yокочама, K. and Iмамото, F. (1987). Transcriptional control of the endogenous $M Y C$ protooncogene by antisense RNA. Proc. Natl. Acd. Sci. USA, 84: 7363-7367.

34. Yoxoyama, K. (1991). Transcriptional Regulation of c-myc protooncogene by antisense RNA. In Prospects for Nucleic Acid Therapy of Cancer and AIDS (E. Wickström, ed.). WileyLiss. Inc. pp. 35-51.

35. Yoкоуама, K. (1992). Antisense RNA induces a nuclear transcription factor to repress the expression of endogenous myc gene. In Antisense RNA and DNA (J.M. Murray, ed.). WileyLiss. Inc. pp. 335-352.

36. Westin, E.H., Wong-Staal, F., Gelmann, E.P., Favera, R.D., Papas, T.S., Lautenberger, J.A., Eva, A., Reddy, E.P., Tronick, S.R., Aronson, S.A., and Gallo, R.C. (1982). Expression of cellular homologues of retroviral onc genes in human hematopoietic cells. Proc. Natl. Acad. Sci. $U S A, 79: 2490-2494$.

(Received for publication, September 18, 1992 and in revised form, November 20, 1992) 